\title{
MELHORIA DOS PROCESSOS EXTRATIVISTAS NA APICULTURA A LUZ DA ENGENHARIA DA QUALIDADE
}

\section{IMPROVING EXTRACTIVE PROCESSES IN BEEKEEPING IN THE LIGHT OF QUALITY ENGINEERING}

\author{
Marina Lunga Dias Sousa*E-mail: marinalungads@gmail.com \\ Francisca Jeanne Sidrim de Figueiredo Mendonça* E-mail: jeanne.sidrim@urca.br \\ Bruna Stephany Coelho de Souza*E-mail: bruna.stephany@urca.br \\ Amanda Duarte Feitosa* E-mail: amandadfeitosa@hotmail.com \\ Ana Karine Gomes Duarte** E-mail: karine.duarte@urca.br \\ Universidade Regional do Cariri (URCA), Crato, CE \\ Universidade Federal de Pernambuco (UFPE), João Pessoa, PE
}

\begin{abstract}
Resumo: A apicultura é uma atividade extrativista sustentável, que resulta em uma gama de produtos, sendo o mel o que possui maior valor, sua rentabilidade é responsável pela subsistência de inúmeras famílias. O Brasil está entre os quinze maiores produtores de mel do mundo, devido a sua alta exploração e comercialização, tornando-se causa de disputa entre consumidores por seu baixo percentual de contaminação. No entanto, a sua produção artesanal e adequações produtivas têm sido gargalo na produção inócua. O presente trabalho busca identificar os principais contaminadores dentro do ambiente extrativo, com o propósito de diminuí-los ou levá-los à extinção. Foram utilizadas ferramentas da qualidade como Diagrama Causa e Efeito e o Gráfico de Pareto, aliadas as boas práticas de fabricação e o Sistema de Análise de Perigos e Pontos Críticos de Controle (APPCC), objetivando elencar estrategicamente os meios contaminadores e propor um plano de ação mútuo aos produtores bem como recomendação de mudanças nos arranjos físicos, aumentando a qualidade do mel da região e, por consequência, elevar seu valor comercial.
\end{abstract}

Palavras-chave: Mel. Apicultura. Qualidade. Ferramentas. Produção.

\begin{abstract}
Beekeeping is a sustainable extractive activity, which results in a range of products, being honey the one with the highest value, its profitability is responsible for the subsistence of numerous families. Brazil is among the fifteen largest honey producers in the world, due to its high exploitation and commercialization. However, its artisanal production and productive inadequacies have been a bottleneck in harmless production. The present work seeks to identify the main contaminants within the extractive environment, to reduce or eliminate them. Quality tools were used, such as the Cause and Effect Diagram and Pareto Graph, allied to good manufacturing practices and the Hazard Analysis and Critical Control Points System (HACCP), aiming to strategically list the means of contaminants and propose a mutual action plan to producers as well as a recommendation for changes in physical arrangements, aiming to increase the quality of honey and raise its commercial value.
\end{abstract}

Keywords: Honey. Beekeeping. Quality. Tools. Production.

\section{INTRODUÇÃO}

A atividade extrativista surgiu da necessidade do ser humano de extrair recursos naturais para seu próprio consumo, e tornou-se um método com fins 
lucrativos. Atividade apícola é uma das atividades extrativistas de agricultura familiar sustentável, viabilizada pelo aproveitamento da vegetação nativa vigente da região e da capacidade produtiva das abelhas (WEGNER, FARIAS, WOLFF, 2015).

A extração do mel apresenta rentabilidade, uma vez que a maior parte de seus produtos tem retorno financeiro. Como produto alimentício e medicinal produz a cera, utilizada na indústrias de cosméticos, medicamentos e velas, na fabricação de polidores e vernizes, no processamento de alimentos e na indústria tecnológica; o própolis, usado nas indústrias de cosméticos e farmacêutica; o pólen apícola, em virtude do seu alto valor nutritivo, é usado como suplementação alimentar; a geleia real, utilizada na indústria de cosméticos e medicamentos; apitoxina, veneno das abelhas operárias de Apismellifera purificado, que possui ação antirreumática, sendo assim comercializado para farmácias de manipulação e indústrias de processamento químico, em razão da sua ação tóxica (SEBRAE, 2009).

Diante desta vasta possibilidade econômica emergente da atividade apícola, do valor agregado, alta demanda e preços favoráveis a venda, o Brasil vem passando por um processo de modernização e adoção de técnicas mais elaboradas, deixando de ser um produto artesanal de consumo interno e tornando-se um produto empresarial, voltado ao mercado externo (SOUZA et al., 2016). O que o destacou e possibilitou ocupar a decima primeira posição dentre os países produtores e exportadores do mundo, com um valor produtivo de $\mathrm{R} \$ 513,9$ milhões (IBGE, 2017).

O nordeste brasileiro produziu 12.757,6 toneladas de mel em 2017 e é responsável pela produção de $30 \%$ da produção anual do país, sendo o Piauí detentor de $25 \%$ da produção do nordeste (IBGE,2019). O mel nordestino apresenta um enorme diferencial uma vez que seus índices apontam baixa contaminação por pesticidas e por resíduos de antibióticos, o que faz com que os Estados Unidos, maior receptor do mel brasileiro, desembolse maior remuneração ao produto, se comparado a outros países exportadores (IBGE, 2019).

Tendo em vista a importância brasileira na cadeia produtora e exportadora de mel, além da necessidade de ofertar um produto puro ao mercado, o presente trabalho buscou conhecer melhor a real situação do sistema de produção do interior piauiense, analisar e propor melhorias a partir da implementação de ferramentas da qualidade no intuito de aprimorar a gestão do sistema de produção apícola, buscando contribuir para o crescimento da atividade na região. 
Esse trabalho teve sua pesquisa realizada com produtores de mel pertencentes a uma associação de apicultores de Picos-PI, a fim de mensurar os principais meios contaminadores do mel, utilizando os conhecimentos da engenharia da qualidade e técnicas do sistema APPCC (Análise dos Perigos e Pontos Críticos de Controle) voltados para o âmbito da contaminação física. Por fim foi apresentado um plano de melhorias no intuito de reduzir os meios contaminadores, aumentando a qualidade do mel, produto apícola em estudo.

\section{REFERENCIAL TEÓRICO}

\subsection{Gestão da Qualidade}

A relação cliente qualidade é um elo paralelo que exerce influência direta sobre o outro, principalmente no referente ao ramo produtivo. O cliente possui gigantesco domínio sobre o mercado, que por sua vez busca conhecer o demandador de seu produto e entender suas necessidades, para que com isso possa oferecer um produto com a maior conformidade possível, satisfazendo os clientes/consumidores que lhes usam ou consomem (GONÇALVES; LUZ, 2016).

Quando o assunto é alimento, a qualidade é algo indispensável, pois ela é a responsável pela garantia e segurança dos produtos. Portanto a indústria alimentícia deve obedecer a algumas leis e regulamentações impostas pelo regimento do país a qual ela se encontra, no Brasil as leis regulamentadoras são estabelecidos pelo Ministério da Agricultura, com a Portaria n 40/1998 (BRASIL, 1998) e o Ministério da Saúde, com a Portaria no 1428/1993 (BRASIL, 1993), e são regulamentadas pela ANVISA, que ainda conta com a certificação da ISO 22000 (International Organization for Standardization), que refere-se ao Sistema de Gestão da Segurança de Alimentos.

Para obtenção de melhorias nos produtos e processos é essencial o uso e de ferramentas que darão o devido suporte a gestão. As conhecidas ferramentas da qualidade possibilitam não somente a obtenção de um padrão, mas a garantia de processos mais enxutos, se levado em consideração que se trata de um processo de melhoria contínua (BORGES et al., 2017). Serão apresentadas neste referencial as ferramentas utilizadas na realização deste estudo: Gráfico de Pareto, Fluxograma, Diagrama de Ishikawa ou Gráfico de Causa e Efeito, 5W2H. 


\subsubsection{Fluxograma}

O fluxograma se constitui como uma ilustração gráfica de uma determinada atividade ou processo. Para Galvão (2017) a ferramenta é um "instrumento que permite a compreensão rápida do fluxo atual de determinado processo, a identificação de possíveis falhas, etapas desnecessárias e atividades redundantes".

\subsubsection{Causa e efeito}

Conhecido como diagrama Ishikawa ou diagrama espinha de peixe, o diagrama de causa e efeito foi proposto por Ishikawa em 1943. Esta ferramenta contribui para sugestão de melhorias de processo, baseado na estruturação de causas e efeitos, distribuídas em "6M", sendo eles: Mão de Obra- referente a influência de pessoas no processo; Máquina- referente a influência do maquinário e ferramentas; MatériaPrima- referente a qualidade e do tipo de material utilizado; Medida- métricas utilizadas para mapear o desenvolvimento das atividades; Meio Ambiente- influência do meio no desenvolvimento do processo; Método- como os métodos utilizados no trabalho interferem na realização dos mesmo (BACKES; VANIN; BELCHOR, 2018).

\subsubsection{Pareto}

Trata-se de um gráfico de barras ordenadas de forma sequencial da maior a menor ocorrência, é uma ferramenta de priorização de ações para redução de problemas, baseado na teoria dos $80 \%$ de consequências advindas dos $20 \%$ de causas, desenvolvido pelo engenheiro e economista Vilfredo Pareto, apresentando ao gestor a ordem a qual devem ser resolvidas as causas e elencando a ordem de problemática das dificuldades (COELHO et al., 2016).

Essa ferramenta permite a visualização categorizada das causas mais notórias e facilita a priorização dos principais problemas a serem resolvidos (PENEDO et al., 2020).

\subsection{4 $5 \mathrm{~W} 2 \mathrm{H}$}

O 5W2H é na verdade uma ferramenta checklist de atividade que visa facilitar 
a identificação das variáveis de um processo que devem ser trabalhadas com 0 máximo de clareza e eficiência (BONATTO et al., 2018). Seu nome vem da língua inglesa, e trata-se de expressões interrogativas que devem servir de guia para elaborar o de plano de ação, são elas: what (O que), who (Quem), where (Onde), when (Quando), why (Por que), how (Como) e how much (Quanto), esse plano é apresentado na forma de um quadro que permite a visualização desde a causa, até sua solução sob respaldo de apresentação de métodos para obtenção do resultado desejado.

\subsection{Boas práticas de fabricação}

Manual que descreve os pré-requisitos básicos, critérios de qualidade e segurança a partir da normatização de processos, é baseado na APPCC, no entanto as boas práticas de fabricação são voltadas principalmente para análise de circunstâncias ambientais, equipamentos, utensílios, recursos humanos e controle de qualidade (ANVISA, 2015).

Para Lima (2018) o princípio básico para adequação ao manual de boas práticas de fabricação é a busca por uma produção de modo mais higiênica possível, abrangendo desde a higiene pessoal que se refere a uniformes e acessórios; a higiene ambiental que está relacionada às condições da edificação em questão, que são paredes, pisos; higiene operacionais referente às condições do processo, e como o mesmo evita certos tipos de contaminação; procedimentos limpeza e desinfecção relacionadas a métodos de higienização dos materiais necessários e pertinentes a produção; controle integrado de pragas que possui o intuito de diminuir e controlar a população de pragas a níveis considerados.

O manual de boas práticas voltado ao processamento apícola destaca seus principais riscos de contaminação, apresentando também as principais práticas preventivas para redução do esforço físico do trabalhador, e redução dos riscos oferecidos ao consumidor e a qualidade do produto (SEBRAE, 2009). 


\subsection{Sistema de Análise de Perigos e Pontos Críticos de Controle (APPCC)}

Trata-se de um sistema que possibilita a garantia de segurança alimentar, é internacionalmente reconhecido e aceito, pois busca a isenção de qualquer tipo de contaminação, seja ela microbiana, física ou química, consiste na identificação e avaliação e controle de pontos críticos, para eliminação de possíveis agentes causadores de danos ao produto final. Portanto se trata de um método cauteloso de inspeção da produção de ramal alimentício, aprovado pelo Food and Drug Adminstration e pelo Mundo Organização da Saúde Codex Alimentarius Comissão (ROCHA et al., 2018).

\section{MÉTODO DE PESQUISA}

O presente trabalho de enquadra como uma pesquisa aplicada, qualitativa, de abordagem exploratória, sob método de estudo de caso múltiplo. Pois segundo GANGA (2012) o propósito do trabalho é tido como aplicado. Quanto a sua abordagem é de caráter exploratório, pois visa estudar um problema pouco explorado, norteado pela análise do campo de estudo, com processo investigativo, além de possuir um embasamento viabilizado por pesquisas bibliográficas (GANGA, 2012).

Como a base do processo investigativo será composta por análise e aplicação de questionários para identificação de conhecimento e aplicação das Boas Práticas de Fabricação (BFF), gerando dados que serão quantificados, tornando-o um trabalho de abordagem qualitativa, resultante da interpretação do ambiente a qual a problemática acontece (CAUCHICK, 2010). Já a técnica utilizada neste trabalho classifica-o como um estudo de caso múltiplo integrado, por se tratar da investigação de um fenômeno em seu contexto real por meio da análise aprofundada possibilitado pela utilização de evidências de diversas fontes distintas, envolvendo além da pesquisa bibliográfica, a descrição de determinada realidade, permeado sob lógica de replicação (MARTINS, 2014).

O trabalho foi possibilitado através de um levantamento de dados bibliográficos sobre o tema em questão, que permeou e possibilitou um melhor conhecimento. Essa revisão da literatura teve enfoque principalmente nos assuntos relacionados a APPCC e as boas práticas da produção alimentícia de origem animal, a fim de ampliar o conhecimento da ferramenta. 
Como instrumento de coleta de dados foram utilizados questionários projetados para coletar informações essenciais de campo de trabalho, aplicados a seis apicultores de forma direta, com objetivo de identificar a relação do produtor com a profissão, a situação do ambiente a qual era extraído o seu produto, e se teria algum conhecimento sobre as normas e necessidades higiênicas básicas da produção apícola.

Durante aplicação dos questionários foi também observado as casas de méis, que permitiu uma análise primária sobre a condição do ambiente de extração e culminou no desenvolvimento do fluxograma produtivo. Para identificação dos reais riscos físicos a qual se encontrava suscetível o mel com o auxílio do manual de boas práticas e do sistema de análise de perigos e pontos críticos de controle (APPCC), seus dados foram armazenados utilizando o diagrama de Causa e Efeito. Após listados e analisados os riscos físicos utilizou-se o gráfico de Pareto para identificação dos principais e mais presentes riscos que comprometem a qualidade do mel da região.

Detido de todas as informações necessárias, sob respaldo do Regimento da Secretaria Nacional de Defesa Agropecuária, utilizado para inspeção do produto de alimentício de origem animal do Ministério da Agricultura, Pecuária e Abastecimento e pelo manual de Boas Prática de Fabricação, foi produzido o plano de melhorias, também conhecido como $5 \mathrm{~W} 2 \mathrm{H}$, no entanto, o utilizado do trabalho foi o $5 \mathrm{~W} 1 \mathrm{H}$, uma vez que o campo quanto da ferramenta é muito variante de acordo com a necessidade de cada casa extratora.

\section{ESTUDO DE CASO}

A produção analisada está localizada na cidade de Campo Grande do Piauí, cerca de $300 \mathrm{~km}$ da capital, Teresina. Os produtores são pertencentes a associações apícolas de Picos - Pl e em grande maioria são produtores migrantes, que transportam suas colmeias e maquinário produtivos entre os estados do Piauí, Pernambuco e Maranhão. 


\subsection{Fluxo Produtivo}

O processo de extração de mel inicia-se no campo durante a noite com os trabalhadores vestidos corretamente (Macacão, Luvas, Botas, Máscaras). Estes se encaminham aos apiários, local onde se localizam as caixas de abelha, e a princípio é feito uma triagem da qual permite a identificação das que estão no ponto de serem colhidas, evitando, portanto, trabalho desnecessário.

Concluindo-se a triagem, as caixas que possuem mel são transportadas para as casas de mel, ou barracões - nome utilizado na região. Nessa nova etapa, que acontece logo pela manhã, inicia-se realmente o processo de extração do mel. Dentro das caixas, os favos de méis ficam localizados em quadros que geralmente encontram-se cobertos por uma pequena e fina camada de cera. A retirada dessas camadas de cera é conhecida como desoperculação.

A desoperculação é feita sobre uma espécie de mesa, conhecida como mesa desoperculadora, e é nessa mesma que fica armazenada a cera retirada durante o processo, em quadros que serão transportados para a próxima etapa. Quando atingidos um número suficiente de quadros desoperculados, estes são colocados em uma máquina chamada de centrífuga, que executa um movimento giratório em grande velocidade, possibilitando a saída um pouco mais rápida do mel dos favos, sem intervir na sua estrutura.

Ao fim desse processo, o mel escoa para baldes logo após passar por um processo de filtragem, que ocorre na saída da centrífuga com o auxílio de filtros de tela de aço inoxidável ou fio de náilon. Sendo então transportado para grandes tonéis, conhecidos como decantadores, no qual o mel fica durante algum tempo para que o mesmo passe pelo processo de decantação. Essa operação dura cerca de 48 horas e facilita a retirada de qualquer resíduo (cera, abelhas) resultante dos processos anteriores.

Por fim, o mel se encontra pronto para armazenamento final, que por sua vez, pode ser feito em grandes tambores, caso a produção seja em larga escala, em baldes ou até mesmo o envase direto nos recipientes específicos, caso o produtor também seja o escoador de seu produto final.

Os demais itens citados são mais utilizados quando o produto final é repassado a associações e/ou empresas que o escoaram a outras regiões, dentro e fora do país. 
Figura 1 - Fluxograma do Processo de colheita e extração do mel

Coleta de Mel no Campo

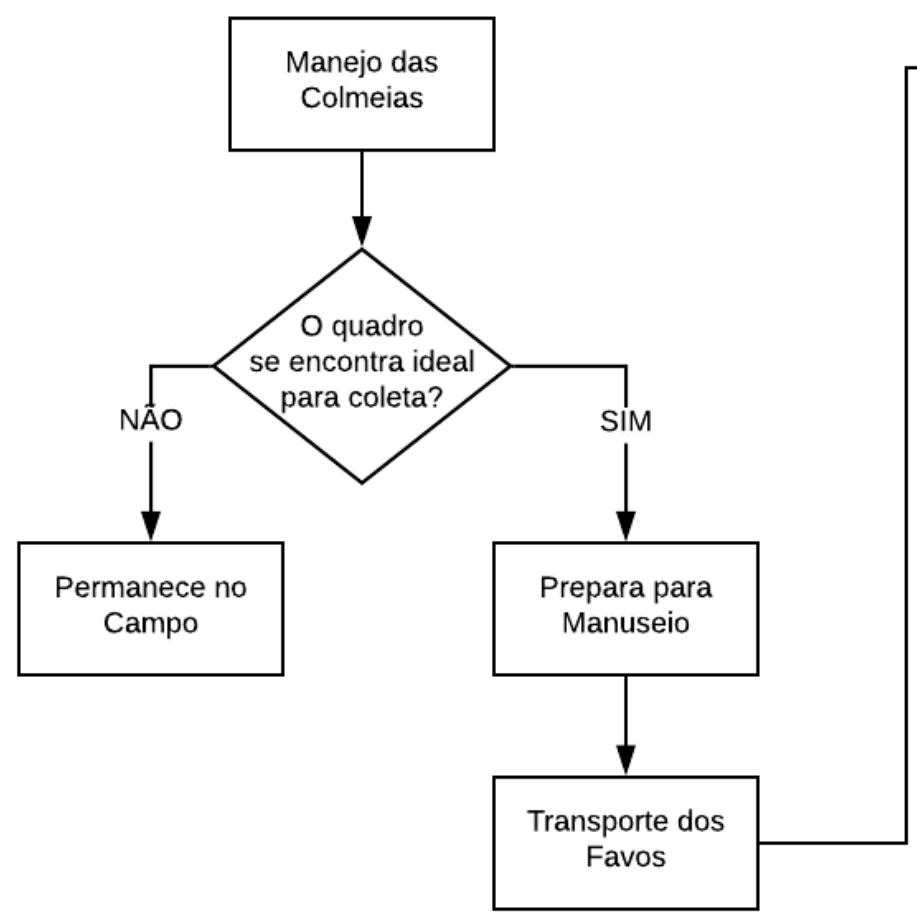

Processamento na Casa de mel

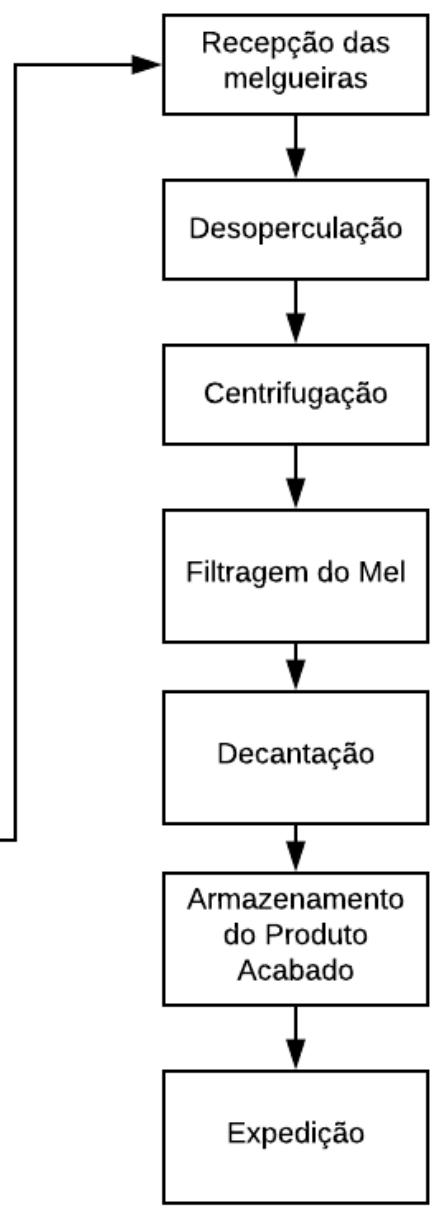

Fonte: Os autores (2020).

\subsection{Apresentação individual dos produtores}

Em busca de identificar os principais meios e processos contaminadores do mel da região, foi realizado um estudo de caso com seis apicultores pertencentes a associação apícola da microrregião de Picos - PI, intitulada como capital do mel, que por se encontrar em um entroncamento rodoviário, permite a recepção e escoamento de grande quantidade do produto, proveniente de produtores da região e de estados vizinhos. Todavia decorrente das grandes temporadas de secas e escassez de incentivos governamentais para desenvolvimento da atividade, seus produtos vêm apresentando decréscimo de qualidade, afetando diretamente sobre o valor final do produto. 
Quadro 1 - Características Gerais dos produtores

\begin{tabular}{|l|l|l|l|l|l|}
\hline \multicolumn{1}{|c|}{ Apicultor } & \multicolumn{1}{|c|}{ Sexo } & $\begin{array}{c}\text { Tempo de } \\
\text { Trabalho }\end{array}$ & $\begin{array}{c}\text { Tipo de } \\
\text { apicultura }\end{array}$ & $\begin{array}{c}\text { Produção } \\
\text { anual }\end{array}$ & Escolaridade \\
\hline Produtor 1 & Masculino & +20 anos & Fixa & $4000 \mathrm{~kg}$ & $\begin{array}{l}\text { Ensino } \\
\text { Superior }\end{array}$ \\
\hline Produtor 2 & Masculino & $10-20$ anos & Migratório & $5000 \mathrm{~kg}$ & $\begin{array}{l}\text { Ensino } \\
\text { Superior }\end{array}$ \\
\hline Produtor 3 & Masculino & $10-20$ anos & Migratório & $3000 \mathrm{~kg}$ & $\begin{array}{l}\text { Ensino } \\
\text { Superior }\end{array}$ \\
\hline Produtor 4 & Masculino & $10-20$ anos & Migratório & $10000 \mathrm{~kg}$ & Ensino Médio \\
\hline Produtor 5 & Feminino & $10-20$ anos & Migratório & $3000 \mathrm{~kg}$ & Ensino Médio \\
\hline Produtor 6 & Masculino & -5 anos & Fixa & $1925 \mathrm{~kg}$ & Ensino Médio \\
\hline
\end{tabular}

Fonte: Os autores (2020)

A atividade apícola possui baixa complexidade e desenvolve-se em poucas etapas, com a utilização de poucas máquinas e ferramentas, o que possibilita que independente das diferenças entre as unidades extratoras, obedecem ao mesmo fluxo produtivo, distinguindo-se com relação ao layout da casa do mel, EPI's e técnicas utilizadas.

Foram realizadas análises dos locais de trabalho dos produtores, observandose possíveis irregularidades e propostas mudanças para aperfeiçoamento da produção.

\subsubsection{Produtor 1}

O produtor trabalha no ramo há mais de 20 anos, com uma produção anual de $4000 \mathrm{~kg}$ de mel, utiliza de uma apicultura fixa na região a qual reside. Seu produto final é escoado principalmente pra associação apícola a qual é pertencente em Picos - PI.

Apesar de apresentar um espaço físico limpo, com maquinário do material determinado pelos órgãos demandadores da lei, a estrutura física da unidade extratora apresenta inconformidades, além de que o apicultor não tem controle sobre o acesso a parte interna do barracão.

Quadro 2 - Conformidades e Não conformidades da Casa de Mel 1

\begin{tabular}{|l|l|}
\hline \multicolumn{1}{|c|}{ Conformidades } & \multicolumn{1}{c|}{ Não Conformidades } \\
\hline $\begin{array}{l}\text { Casa de mel comporta a produção mesmo } \\
\text { quando a produção excede o tradicional }\end{array}$ & $\begin{array}{l}\text { Casa de mel não obedece aos requisitos físicos } \\
\text { determinados por lei }\end{array}$ \\
\hline Maquinas de acordo com os padrões & Sem banheiro \\
\hline lluminação natural e artificial adequada & Inexiste um local para higienização das mãos \\
\hline Separação física de outras áreas & $\begin{array}{l}\text { Material colhido no campo possui acesso direto } \\
\text { ao ambiente extrativo }\end{array}$ \\
\hline Portas e janelas metálicas e teladas & \\
\hline
\end{tabular}

Fonte: Os autores (2020). 
A estrutura física da unidade extratora apresenta inconformidades, além de que o apicultor não tem controle sobre o acesso a parte interna do barracão.

\subsubsection{Produtor 2}

O produtor 2 atua no ramo há mais de 15 anos, trabalha com apicultura migratória e possui uma produção anual de cerca de $5000 \mathrm{~kg}$ de mel, translada seus equipamentos e maquinários aos estados do Maranhão, Pernambuco e Piauí. O quadro de funcionários é composto por cerca de 3 funcionários fixos, sendo expansível de acordo com a demanda. O mel, seu produto final, é escoado de acordo com a região onde o mesmo se encontra.

No referente a estrutura física da unidade extratora, o produtor encontra-se dentro dos padrões, apesar de não a utilizar de forma correta, por atestar ser um trabalho desnecessário. A casa de mel possui uma boa área, comportando até o dobro de sua produção na temporada em questão. No entanto, em seu espaço "livre" o produtor armazena alguns de seus utensílios e ferramentas, sob a alegação de que poderá remover se necessita da área.

Quadro 3 - Conformidades e Não Conformidades da Casa de Mel 2

\begin{tabular}{|l|l|}
\hline \multicolumn{1}{|c|}{ Conformidades } & \multicolumn{1}{c|}{ Não Conformidades } \\
\hline $\begin{array}{l}\text { Casa de mel comporta a produção mesmo } \\
\text { quando a produção excede o tradicional }\end{array}$ & $\begin{array}{l}\text { Presença de material desnecessário dentro da } \\
\text { casa de mel }\end{array}$ \\
\hline Maquinas dentro dos padrões & $\begin{array}{l}\text { Material colhido no campo possui acesso direto } \\
\text { ao ambiente extrativo }\end{array}$ \\
\hline lluminação natural e artificial adequada & Sem banheiro \\
\hline Separação física de outras áreas & $\begin{array}{l}\text { Não obedece a estrutura base para produção } \\
\text { inócua, apesar de possuir }\end{array}$ \\
\hline Porta e janela metálicas e teladas & \\
\hline Possui local para higienização das mãos & \\
\hline Disponibiliza EPl's & \\
\hline
\end{tabular}

Fonte: Os autores (2020).

\subsubsection{Produtor 3}

Este produtor ingressou no ramo por influência familiar e possui produção de cerca de $3000 \mathrm{~kg}$, optou pela migração de suas colmeias, principalmente para o estado do Maranhão. Seu quadro de funcionários é restrito e a mão de obra disponível no momento extrator, não possuindo nenhum funcionário fixo, o que possibilita uma mão 
de obra mais barata, porém com deficiência em qualificação, exigindo do produtor ensinamentos antes de começar a extração do mel de fato.

A casa extratora trata-se da adequação de uma simples casa de pequenas dimensões que, de acordo com ele, cumpre todas as suas necessidades. A reforma e transformação do ambiente em um barracão não obedece a todos os requisitos exigidos para produção apícola.

Quadro 4 - Conformidades e Não conformidades da Casa de Mel 3

\begin{tabular}{|l|l|}
\hline \multicolumn{1}{|c|}{ Conformidades } & \multicolumn{1}{c|}{ Não Conformidades } \\
\hline Casa de mel comporta a produção & $\begin{array}{l}\text { Casa de mel não se enquadra nos requisitos } \\
\text { mínimos para produção inócua }\end{array}$ \\
\hline Máquinas dentro dos padrões & $\begin{array}{l}\text { Material colhido no campo possui acesso direto } \\
\text { ao ambiente extrativo }\end{array}$ \\
\hline lluminação natural adequada & lluminação artificial inadequada \\
\hline Separação física de outras áreas & \\
\hline Porta e janelas metálicas e teladas & \multicolumn{2}{|c|}{} \\
\hline Possui local para higienização das mãos & \\
\hline
\end{tabular}

Fonte: Os autores (2020)

\subsubsection{Produtor 4}

Trabalhando há mais de 10 anos no mercado apícola, o produtor optou pela apicultura migrante, uma vez que o período produtivo da região é bem definido e é economicamente mais viável optar pela migração. Sua produção anual gira em torno de $10.000 \mathrm{~kg}$ de mel e migra entre os estados do Maranhão, Ceará e Piauí. Apesar de sua rotatividade, o produtor não possui funcionários fixos e conta com a ajuda de alguns pequenos apicultores, ele translada a matéria prima em troca do trabalho prestado ou até mesmo busca essa mão de obra na cidade a qual ele se fixa na temporada.

No referente à sua unidade extratora do Piauí, o local utilizado possui uma área adequada a sua produção, diferente das demais casas de mel em estudo, essa apresenta um local (sem acesso direto à casa de mel) para que os funcionários façam suas necessidades. 
Quadro 5 - Conformidades e Não Conformidades da Casa de Mel 4

\begin{tabular}{|l|l|}
\hline \multicolumn{1}{|c|}{ Conformidades } & \multicolumn{1}{c|}{ Não Conformidades } \\
\hline Casa de mel comporta a produção & $\begin{array}{l}\text { Presença de material desnecessário dentro da } \\
\text { casa de mel }\end{array}$ \\
\hline Maquinas dentro dos padrões & $\begin{array}{l}\text { Material colhido no campo possui acesso direto } \\
\text { ao ambiente extrativo }\end{array}$ \\
\hline Iluminação natural e artificial adequada & Não possui controle de acesso a casa de mel \\
\hline Separação física de outras áreas & $\begin{array}{l}\text { A circulação de ar é restrita a entrada direta pelo } \\
\text { portão principal, não possuindo janelas }\end{array}$ \\
\hline $\begin{array}{l}\text { Local de higiene pessoal sem acesso direto ao } \\
\text { ambiente produtivo }\end{array}$ & $\begin{array}{l}\text { Não obedece aos requisitos estruturais de uma } \\
\text { casa de mel }\end{array}$ \\
\hline Possui local para higienização das mãos & \multicolumn{2}{|l}{} \\
\hline Porta metálicas com presença de telas & \multicolumn{2}{|l}{} \\
\hline
\end{tabular}

Fonte: Os autores (2020).

Por trabalhar com a troca de prestação de serviços, sua unidade extratora não apresenta controle ou fiscalização higiênica das pessoas que circulam no ambiente.

\subsubsection{Produtor 5}

Essa produtora migra suas colmeias para algumas regiões no estado do Pernambuco. Sua unidade extratora conta com um forro que impede a contaminação direta de seu produto com os detritos lançados do telhado da unidade. No entanto, o armazenamento dos produtos de extração é feito dentro do local destinado a extração, o que permite o transporte, involuntariamente de poeira e detritos acoplados nas caixas no momento da retirada do apiário.

O layout da sua unidade é de pequeno porte e compartilhado com mais alguns apicultores de seu interior. No referente a sua produção, ele comporta e cumpre com todas as necessidades produtivas, porém por ser compartilhado, a disposição dos equipamentos e maquinários não apresenta eficiência, por conter muito fluxo. 
Quadro 6 - Conformidades e Não Conformidades da Casa de Mel 5

\begin{tabular}{|l|l|}
\hline \multicolumn{1}{|c|}{ Conformidades } & \multicolumn{1}{c|}{ Não Conformidades } \\
\hline Casa de mel comporta a produção & $\begin{array}{l}\text { Presença de material desnecessário dentro da } \\
\text { casa de mel }\end{array}$ \\
\hline Maquinas dentro dos padrões & $\begin{array}{l}\text { Material colhido no campo possui acesso direto } \\
\text { ao ambiente extrativo }\end{array}$ \\
\hline Iluminação natural e artificial adequada & Máquina manual \\
\hline Separação física de outras áreas & Unidade extratora compartilhada \\
\hline Porta metálica com presença de telas & \\
\hline Possui local para higienização das mãos &
\end{tabular}

Fonte: Os autores (2020).

\subsubsection{Produtor 6}

Dentre os produtores analisados, esse é o mais recente ingressante no ramo apícola, perfazendo menos de 5 anos de trabalho, encontrando-se ainda em processo de adaptação e adequação as técnicas da área. O produtor afirma não possuir conhecimento avançado sobre as práticas e necessidades básicas determinadas por lei, porém tenta manter o ambiente e as ferramentas de trabalho no mais perfeito estado. É um apicultor de pequeno porte e não conta com mão de obra fixa e sim a prestação mútua de serviços dos demais apicultores da região. Logo, seu produto é escoado somente para a associação a qual pertence.

Quadro 7 - Conformidades e Não conformidades da Casa de Mel 6

\begin{tabular}{|l|l|}
\hline \multicolumn{1}{|c|}{ Conformidades } & \multicolumn{1}{c|}{ Não Conformidades } \\
\hline Casa de mel comporta a produção & $\begin{array}{l}\text { Presença de material desnecessário dentro da } \\
\text { casa de mel }\end{array}$ \\
\hline Máquinas dentro dos padrões & $\begin{array}{l}\text { Não obedece aos requisitos estruturais de uma } \\
\text { casa de mel }\end{array}$ \\
\hline Iluminação natural e artificial adequadas & Não possui controle de acesso a casa de mel \\
\hline Separação física de outras áreas & $\begin{array}{l}\text { Material colhido no campo possui acesso direto } \\
\text { ao ambiente extrativo }\end{array}$ \\
\hline Porta e janelas metálicas com presença de telas & \multicolumn{2}{|c|}{} \\
\hline Possui local para higienização das mãos & \\
\hline
\end{tabular}

Fonte: Os autores (2020).

\section{ANÁLISE DOS RESULTADOS}

Detido de todas as informações obtidas é possível concluir que a perca gradual na qualidade do mel é decorrente da falta de informação e pouco conhecimento sobre o manual de regimento das leis de produção apícola. A possibilidade de uma renda extra e a facilidade de aprendizagem do processo, por se tratar de um trabalho que exige grande esforço físico e pouca teoria, estimula o trabalhador a seguir por tal ramo 
sem o conhecimento necessário e com equipamentos e maquinários improvisados ou de baixa qualidade.

Apesar de se tratar de uma profissão antiga, de mínimos investimentos tecnológicos, e de uma dependência climática fortíssima, há uma enorme presença de jovens dedicados à área, o que apresenta uma possível capacidade de crescimento da profissão, uma vez que se mostram mais adeptos à tecnologia e, assim, adequar-se as necessidades a qual o ramo demanda.

$\mathrm{Na}$ amostra estudada, podemos observar que o grau escolar dos apicultores é bastante alto. Com isso, é notório a correlação com a possibilidade de absorção de novas técnicas e adequação do processo produtivo.

Ainda analisando os dados, podemos perceber que há uma grande variedade de produção entre as apiculturas fixas e migratórias. A apicultura fixa apresenta menor custo se comparada com a apicultura migratória e é mais utilizada por aqueles que não a tem como fonte de renda principal (BARBOSA; SOUSA, 2012). A apicultura migratória requer dos produtores um maior esforço físico e um maior valor econômico, pois sua rotatividade requer uma casa extratora em cada região de exploração apícola ou que o produtor translade seus equipamentos até a região. E mesmo diante desse cenário, os apicultores migratórios representam cerca de $66,7 \%$ dos entrevistados.

Apesar de ser um trabalho exaustivo, o maquinário e ferramentas necessárias a exploração apícola não é de grande complexidade, porém deve-se obedecer a uma série de requisitos, que por sua vez, oscilam desde o material que deve ser utilizado até a estrutura física do ambiente de extração.

Portanto, analisando os itens discutidos e discriminados, elenca-se de forma direta os principais meios contaminadores, resultado de uma análise afinco das entrevistas e visitas aos ambientes produtivos, de acordo com o ambiente que cada um se apresenta. 
Figura 2 - Gráfico de causa e efeito do processo de contaminação do mel

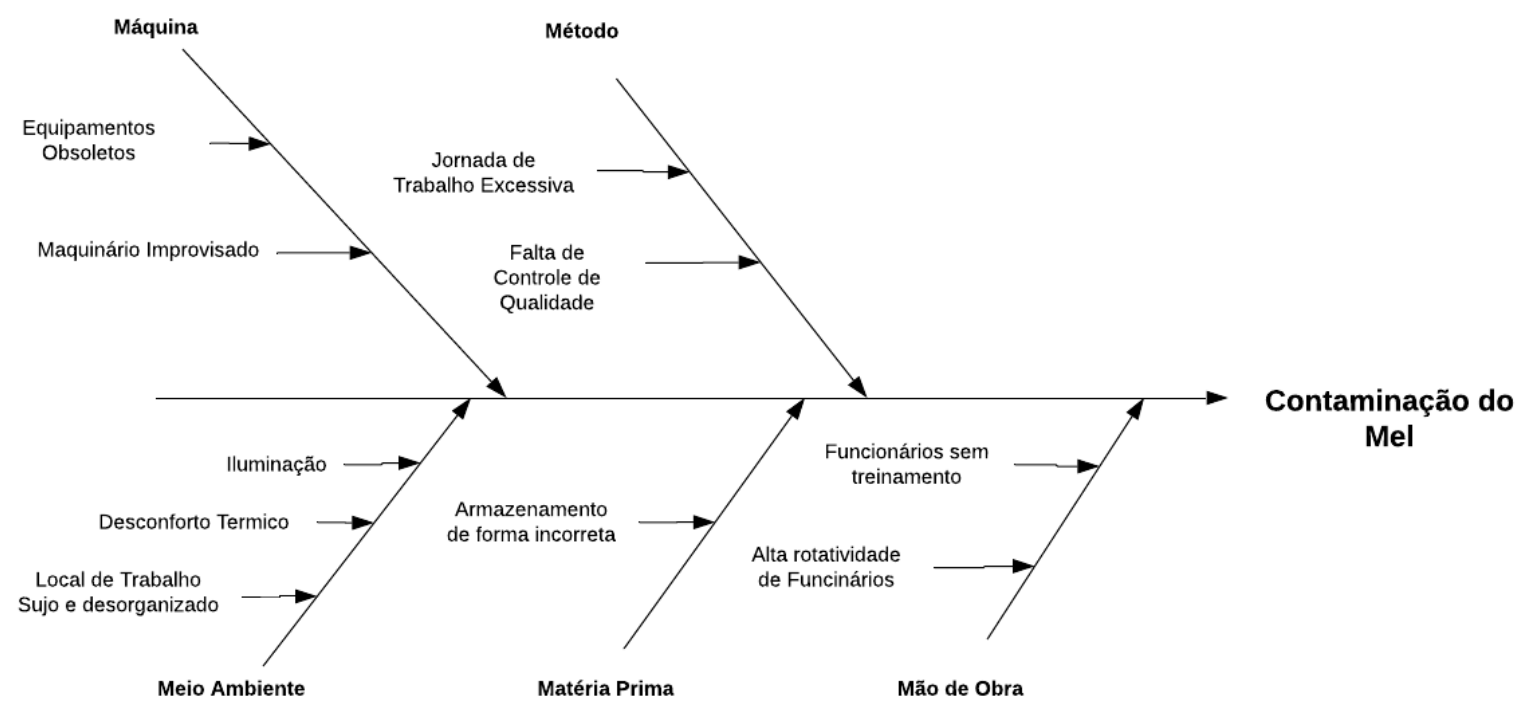

Fonte: Os autores (2020).

Dividindo a análise e agrupando alguns fatores de mesmo nicho, temos:

Quadro 8 - Agrupamento de dados

\begin{tabular}{|l|l|}
\hline Controle de acesso ao barracão & Falta de controle de qualidade \\
\hline $\begin{array}{l}\text { Material do campo com acesso ao ambiente } \\
\text { produtivo }\end{array}$ & Armazenamento incorreto \\
\hline $\begin{array}{l}\text { Material desnecessário dentro do ambiente } \\
\text { produtivo }\end{array}$ & Local de trabalho sujo e desorganizado \\
\hline Quadro de funcionários fixos & Rotatividade de funcionários \\
\cline { 2 - 3 } & Funcionários sem treinamento \\
\hline Maquinário obsoleto e manual & Maquinário improvisado \\
\hline Maquinário obsoleto e manual & Equipamentos obsoletos \\
\cline { 2 - 2 } Circulação de ar restrita & Desconforto térmico \\
\hline lluminação artificial inadequada & \\
\hline Layout de barracão inadequado & \\
\hline Banheiros nas proximidades do barracão & \\
\hline
\end{tabular}

Fonte: Os autores (2020).

Para seleção de forma cordial e com respaldo científico foram utilizados o manual referente práticas de fabricação apícola do SEBRAE de 2009, que apresenta como principais contaminadores físicos dentro do processo produtivo a presença de sujidades (fragmentos de abelhas e vegetação), produtos químicos para limpeza do ambiente, bem como a higienização das ferramentas e elevadas temperaturas como fortes indicadores de alta severidade e risco mediano, já questões como umidade e 
falhas em envaze e lacre do produto final como alta severidade, porém com baixo risco. Confrontando as análises com os métodos e com a tabela de riscos ditadas pela APPCC, obtemos os principais meios contaminadores do estudo em questão, apresentados de acordo com a incidência no campo em análise.

Figura 3 - Agrupamento de dados

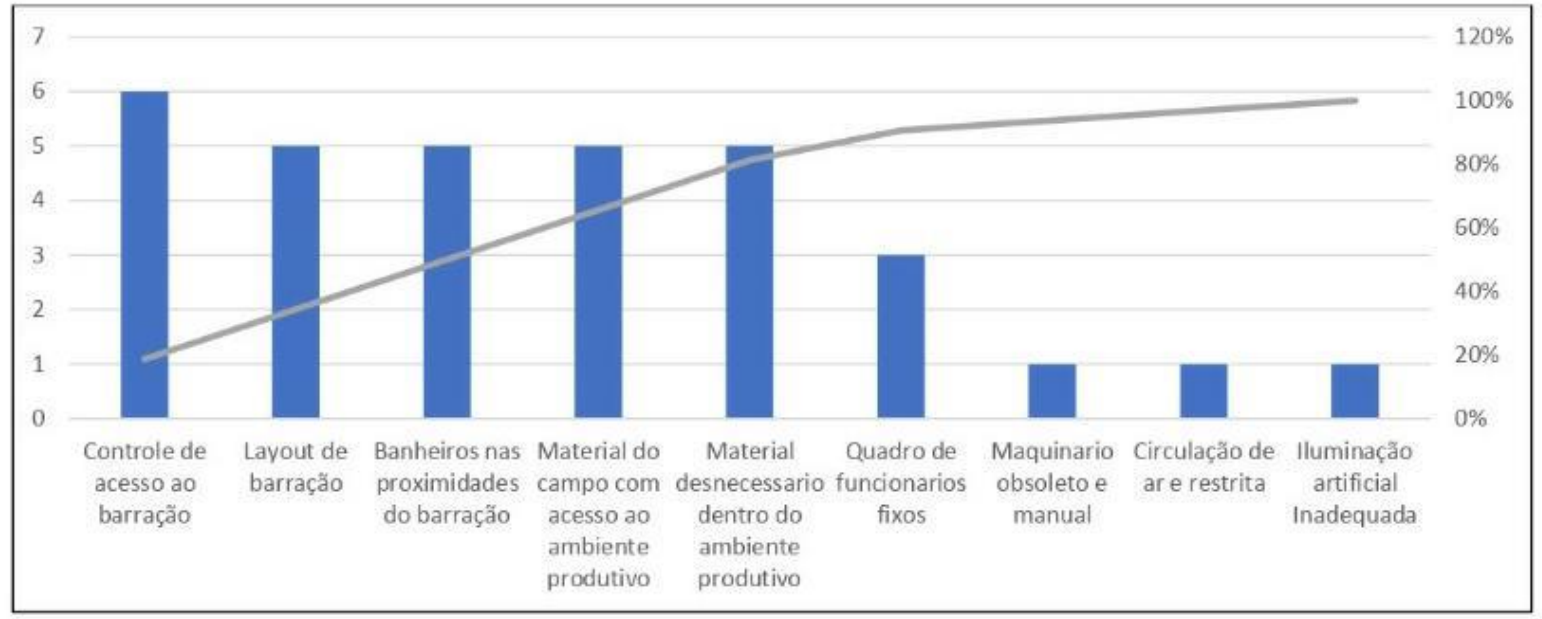

Fonte: Os autores (2020).

\subsection{Layout da Casa de Mel}

Seguindo as ordens das práticas de produção apícola, as unidades extratoras devem encontrar-se isoladas a cerca de 200 metros das residências. Possuir sistema de vedação para evitar os mais diversos contaminadores, com mais de um compartimento para armazenagem dos produtos que chegam dos apiários separados dos que serão extraídos, evitando assim a contaminação direta por translado de materiais, que além da poeira podem animais indesejados a unidade.

Referente a estrutura física do barracão, o mesmo deve possuir portões e janelas vedados com telas para impossibilitar a entrada das abelhas. O piso deve ser do tipo industrial com ralos de escoamento vedados para manutenção da higiene do ambiente, independentemente do tipo de telhado do barracão. Deve ter um forro de material de fácil higienização, com iluminação eficiente devido aos trabalhos realizados a noite.

A iluminação e ventilação devem evitar que se atinja altas temperaturas, para não alterar a composição química do produto extraídos. Banheiros e ambiente de armazenamento de produtos de limpeza não devem possuir acesso direto ao 
barracão, no entanto, deve contar com um lavabo para higienização das mãos, bem localizado, evitando contato direto com o mel.

Diante disso, o único ambiente extrativo que condiz com a estrutura física necessária à extração é a do Produtor 2.

Figura 4 - Esquema de layout da Casa de Mel do Apicultor 2

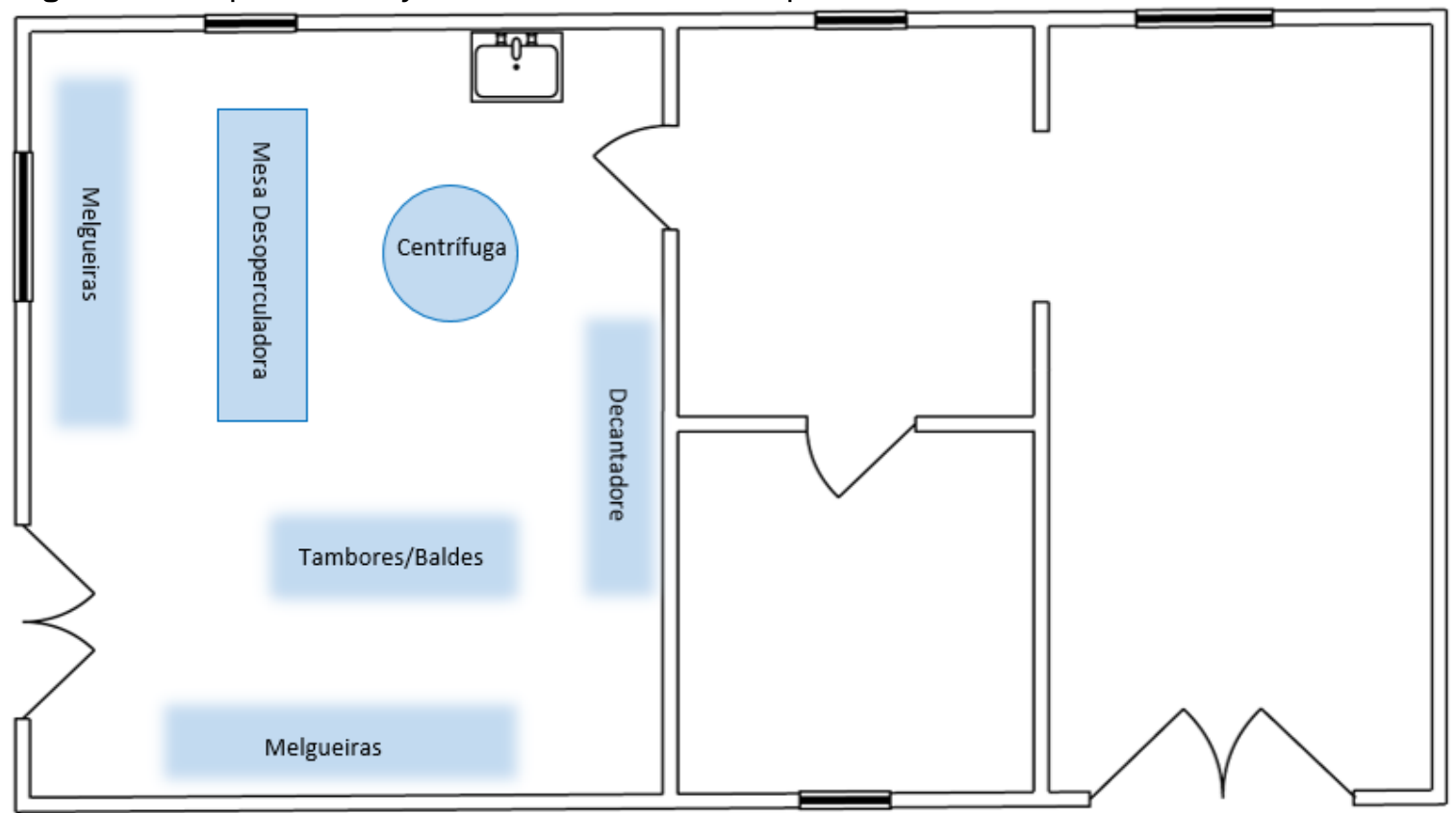

Fonte: Os autores (2020).

Entretanto, é interessante que o mesmo aproveite todo o espaço disponível, sendo o único que possui um ambiente amplo somente para extração. Propõe-se que o seguinte layout para melhoria nos processos. 
Figura 5 - Proposta de esquema de layout da casa de mel do Apicultor 2

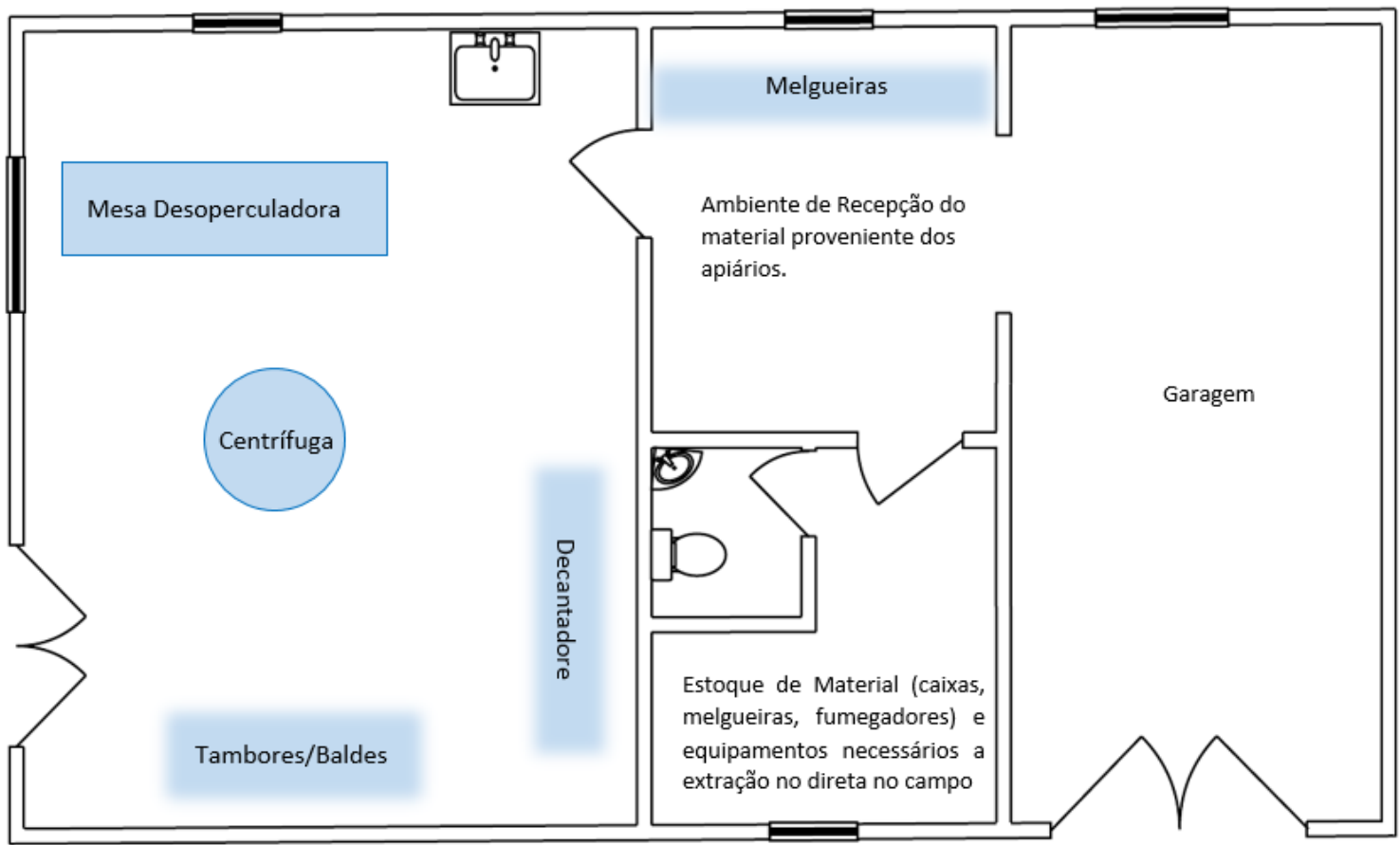

Fonte: Os autores (2020).

\subsection{Plano de ação para redução de meios contaminantes}

Considerando a recorrente incidência da exposição dos meios contaminadores, elaborou-se um plano de ação que visa solucionar este problema com a ajuda das ferramentas apresentadas até o momento.

Quadro 9 - Plano de Ação

\begin{tabular}{|l|l|l|l|}
\hline O que? & Como? & Onde? & Porque? \\
\hline $\begin{array}{l}\text { Controle de acesso } \\
\text { ao barracão }\end{array}$ & $\begin{array}{l}\text { Contratação de funcionários } \\
\text { fixos, e distanciamento de } \\
\text { áreas residenciais. }\end{array}$ & $\begin{array}{l}\text { Na entrada } \\
\text { da casa de } \\
\text { Mel }\end{array}$ & $\begin{array}{l}\text { Porque a falta de controle } \\
\text { possibilita contaminação } \\
\text { proposital ou involuntária do } \\
\text { produto. }\end{array}$ \\
\hline Layout extrativo & $\begin{array}{l}\text { Obtenção de um ambiente } \\
\text { extrativo destinado somente } \\
\text { para este fim. }\end{array}$ & Casa de Mel & $\begin{array}{l}\text { Porque é constante a } \\
\text { utilização de um ambiente } \\
\text { improvisado para a } \\
\text { produção. }\end{array}$ \\
\hline $\begin{array}{l}\text { Banheiros nas } \\
\text { proximidades do } \\
\text { barracão }\end{array}$ & Construção de banheiros & $\begin{array}{l}\text { Áreas } \\
\text { externas dos } \\
\text { barracões }\end{array}$ & $\begin{array}{l}\text { Permitirá aos funcionários } \\
\text { um ambiente privado para } \\
\text { suas necessidades pessoais. }\end{array}$ \\
\hline $\begin{array}{l}\text { Material do campo } \\
\text { com acesso ao } \\
\text { ambiente produtivo }\end{array}$ & $\begin{array}{l}\text { Planejamento e/ou construção } \\
\text { ou adequação de uma área } \\
\text { para apoio do material } \\
\text { proveniente do campo }\end{array}$ & $\begin{array}{l}\text { No espaço } \\
\text { que antecede } \\
\text { o ambiente } \\
\text { extrator }\end{array}$ & $\begin{array}{l}\text { Para evitar o transporte de } \\
\text { animais indesejados, } \\
\text { pedaços de madeira e } \\
\text { detritos de areia e/ou poeira. }\end{array}$ \\
\hline $\begin{array}{l}\text { Material } \\
\text { desnecessário } \\
\text { dentro do ambiente } \\
\text { produtivo }\end{array}$ & $\begin{array}{l}\text { Remoção ou realocação de } \\
\text { qualquer produto ou objeto } \\
\text { desnecessário do espaço } \\
\text { extrativo }\end{array}$ & $\begin{array}{l}\text { Para área } \\
\text { independente } \\
\text { da extração }\end{array}$ & $\begin{array}{l}\text { O armazenamento de } \\
\text { materiais desnecessários } \\
\text { pode atrair insetos e animais } \\
\text { indesejados, bem como } \\
\text { acúmulo de poeira. }\end{array}$ \\
\hline
\end{tabular}

Fonte: Os autores (2020). 


\section{CONSIDERAÇÕES FINAIS}

O objetivo desse trabalho foi identificar os principais meios físicos causadores de contaminação do principal e mais significante produto extrativista apícola, o mel, em uma microrregião de Picos - Pl. Foi apresentado a importância de conhecer e adequar-se as normas vigentes para produção em questão, uma vez que o mercado vem sofrendo com a redução de valor do produto proveniente da contaminação do mel, exigindo maior excelência na produção em questão.

Diante disso, foram utilizadas ferramentas da qualidade para identificação dos mais diversos contaminadores analisados direta e indiretamente com o apoio de entrevistas e análises presenciais dos ambientes extrativos. Para discorrer, analisar e propor melhorias foram utilizados o Diagrama Causa e Efeito que possibilitou a análise visual dos meios contaminadores pertencentes aos seis produtores analisados.

Devido as recorrências contaminantes nos ambientes de estudo, foi utilizado o gráfico de Pareto para apresentação dos principais ambientes e métodos contaminantes, para proposição do plano de ação e com seu auxílio foi apresentado e proposto soluções tangíveis e viáveis para implementação nos ambientes analisados.

As soluções apresentadas referem-se a manuseios de materiais, bem como a necessidade de um controle rigoroso de acesso dentro do ambiente extrativo, passível de solução com a implantação de um quadro fixo de funcionários, possibilitando maior conhecimento da operação por parte do mesmo. No referente ao arranjo físico, foi proposto desde um simples rearranjo até mudanças físicas na estrutura do barracão, possibilitando aperfeiçoamento do processo de produção e melhoria nas condições impostas aos funcionários.

A partir dessas observações, vale salientar que para a implementação proposta é necessário que o apicultor esteja aberto a adequar-se, apresentando as exigências mínimas aos funcionários, disseminando, assim, conhecimento aos demais produtores de forma direta e indireta, uma vez que o estudo proporciona agregação de valor a extração e consequentemente ao valor produtivo do produto da região. 


\section{REFERÊNCIAS}

ANVISA. Agência nacional de vigilância sanitária. Legislação de Boas Práticas de Fabricação. 2015. Disponível em: http://portal.anvisa.gov.br/registros-eautorizacoes/alimentos/empresas/boas-praticas-defabricacao. Acesso em: 12 out. 2019.

BACKES, C. J.; VANIN, A. B.; BAELCHOR, P. M. Aplicação do Diagrama Ishikawa no Mapeamento de Salmonella spp. em Agroindústria de Frangos Camila. In: CONGRESSO BRASILEIRO DE ENGENHARIA DE PRODUÇÃO, 8., 2018. [Anais...]

BRASIL. Ministério da Agricultura, Pecuária e Abastecimento. Portaria no 40/1998. Aprovar o manual de procedimentos no controle da produção de bebidas e vinagres, baseado nos princípios do sistema de analise de perigo e pontos críticos de controle - APPCC. Diário Oficial da União, jan. 1998

BRASIL. Ministério da Saúde. Portaria no.1428, de 26 de novembro de 1993. Regulamento Técnico para Inspeção Sanitária de Alimentos.

BONATTO, F.; MOREIRA, K. Z.; TEIXEIRA, L.C.; DALLAMUTA, J. Aplicação das ferramentas de qualidade na empresa Júnior Brick Engenharia. In: CONGRESSO BRASILEIRO DE ENGENHARIA DE PRODUÇÃO, 8., 2018. [Anais...] https://doi.org/10.22533/at.ed.7701913039

BONATTO, F.; SILVA, V. G.; PONTAROLLO, V. G.; DALLAMUTA, J. Aplicação das ferramentas da qualidade para melhoria do controle de estoque de uma mercearia. In: CONGRESSO BRASILEIRO DE ENGENHARIA DE PRODUÇÃO, 8., 2018.

[Anais...] https://doi.org/10.22533/at.ed.7701913038

BORGES, G. M.; GOMES, E. M.; MOREIRA, F. K.; MOISÉS, F. V. Ferramentas da Qualidade para a melhoria de processos em uma Empresa de Extrusão de Alumínio: um estudo de caso. In: CONGRESSO BRASILEIRO DE ENGENHARIA DE PRODUÇÃO, 7., 2017. [Anais...]

CAUCHICK, P. A. M. Metodologia de pesquisa em engenharia de produção e gestão de operações. Rio de Janeiro: 2010.

COELHO, F.P.S.; SILVA, A.M.; MANIÇOBA, R.F. Aplicação das ferramentas da qualidade: estudo de caso em pequena empresa de pintura. Revista FATEC, v. 3, n.1, p 31-45, out. 2016.

GALVÃO, Gardênia. Manual de Fluxograma. Natal, 2017. ISBN: 978-85-54885-01-4. GANGA, G. M. D. Trabalho de conclusão de curso (TCC) na Engenharia de Produção: um guia prático de conteúdos e forma. São Paulo, 2012.

GONCALVES, R. S; LUZ, M. P. Proposta De Implantação De Ferramentas Da Qualidade No Processo Produtivo De Uma Empresa Alimentícia. In: ENCONTRO NACIONAL DE ENGENHARIA DE PRODUÇÃO, 36., 2016. [Anais...]. p. 12, 2016. 
IBGE. Pesquisa pecuária municipal 2013-2016. v. 44. Rio de Janeiro, 2017.

LIMA, M. D. F. Análise de controle de qualidade de uma indústria alimentícia.

2018. 35 f. Trabalho de conclusão de Curso (bacharelado em Engenharia Química) Universidade Federal Rural do Semi-Árido. Mossoró: UFERSA, 2018.

MARTINS, R.A.; MELLO, C. H. P.; TURRIONI, J. B. Guia para elaboração de monografia e TCC em engenharia de produção. São Paulo: 2014.

PENEDO, L.S. et al. Utilização das ferramentas da qualidade nos processos de manutenção, visando o desperdício de tempo e a produtividade. Revista Teccen, v.13, n. 1, p. 16-24, jan./jun. 2020. https://doi.org/10.21727/teccen.v13i1.2262

ROCHA, A. O. B. et al. Diagnóstico da utilização do sistema APPCC (Análise de Perigos e Pontos Críticos de Controle) em uma indústria de leite e derivados.

Brazilian Journal of Production Engineering, v. 4, p. 135- 159, 2018.

SEBRAE. Manual de segurança e qualidade para apicultura. Série Qualidade e Segurança dos Alimentos, p. 88, 2009.

SOUZA, J. A. et al. a Apicultura Em Rondônia (Amazônia Legal): Estudo De Caso Sobre O Arranjo Produtivo Local Da Apicultura No Cone Sul. Revista Estudo \& Debate, v. 23, n. 2, p. 115-137, 2016. https://doi.org/10.22410/issn.1983$\underline{036 X . v 23 i 2 a 2016.1075}$

WEGNER, J.; FARIAS, B. F.; WOLFF, L. F. O cooperativismo apícola frente aos desafios da sustentabilidade agroecológica em Pedro Osório. In. CONGRESSO BRASILEIRO DE AGROECOLOGIA, 9., 2015. [Anais...]. v. 10, 2015.

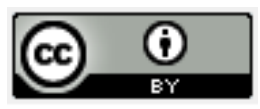

Artigo recebido em: 31/05/2021 e aceito para publicação em: 15/07/2021

DOI: https://doi.org/10.14488/1676-1901.v21i3.4344 